investigations does not apply to his series. According to this formula, the weight of a fish at different ages is a function of the cube of the length. A mathematical investigation of Mr. Russell's average weights by Pearson's "method of moments" shows, however, that the weight of a fish at different ages is to be represented only by a series of the form,

$$
a+b l+c l^{2}+d l^{3}+\ldots .
$$

$l$ being the length of the fishes. It is possible that these terms have each a physical meaning; the fish grows irregularly as its age advances, so that its weight is a function of length, surface, volume, and density, all of which dimensions vary in relation to each other in different phases of the individual lifehistory.

J. J.

\section{WATER SUPPLY.}

$\mathrm{NE}$ of the difficulties besetting the agriculturist in the vast area known as the Great Plains and constituting the central region of the United States is the irregular rainfall. The land is fertile enough, but a recurring series of dry years militates greatly against its effective development. Attempts have been made to remedy the evil by means of artificial irrigation, but so far these efforts have been sporadic and local, and, consequently, they have not produced the completely beneficial results which might be obtained if all the ground water were systematically conserved and utilised.

The United States Government hydrological service, as the result of their investigations, are publishing from time to time a series of water supply papers specially devoted to a consideration of this problem as affecting various localities, and four reports before us (Nos. 345 A, B, C, and D), issued this year, deal with districts in Ok!ahoma, Kansas, and New Mexico. They are useful little pamphlets, affording much detailed information on the geological formation and available water resources of the respective areas. Not the least useful feature, perhaps, is a discussion on the depth and cost of wells, and on the power required for pumping. There is a much-needed caution to prospective irrigators to consider carefully the whole of the outlay likeiy to be involved in any system of artificial irrigation before embarking upon it, lest it should prove to be financially unremunerative and unsound.

Water Supply Paper, No. 340 A (Washington : Government Printing Office, I9I4), of the United States Geological Survey, contains a list of the streamgauging stations situated in the North Atlantic coast drainage basins, and a summary of the reports and publications relating to water resources within this area (1885-1913). It forms a convenient bibliographical index, and should prove most useful for reference purposes to anyone desirous of consulting the literature on the subject.

Three annual reports on the discharge of rivers in the United States are comprised in Water Supply Papers, Nos. 309, 322, and 324 (Washington : Government Printing Office). The first deals with the Colorado River Basin for the year I9II; the other two are for the year I912, and cover the St. Lawrence River Basin and the basins of the South Atlantic coast and eastern Gulf of Mexico respectively. The numerous observations made have been carefully compiled and tabulated, and, in conjunction with those

1 Paper $345 a$ : Preliminary Report on Ground Water for Irrigation in in the vicinity of Wichita, Kansas. Paper $345 \mathrm{~b}$ : Ground Water for Irrigation in the vicinity of Enid, Oklahoma. Paper $345 c$ : Underground Water of Luna County, New Mexico. Paper $345 d$ : Ground Water for Irrigation in the valley of North Fork of Canadian River, near Oklahoma City, Oklahoma, Washington, Igr4. Government Printing Office.

$$
\text { NO. } 2342 \text {, VOL. } 94]
$$

previously published, form a very useful scientific record of stream flow and discharge in the areas specified. Each pamphlet has an introductory note on the methods employed in gauging, and, in the I912 reports, there are some interesting photographs and diagrams.

\section{THE AUSTRALIAN MEETING OF THE BRITISH ASSOCIATION.}

\section{SECTION $\mathrm{H}$. \\ ANTHROPOLOGY.}

Opening Address by Sir Everard im Thurn, C.B., K.C.M.G., President of the Section.

\section{A Study of Primitive Character.}

Civilisarion and "savagery"-for unfortunately it seems now too late to substitute any term of less misleading suggestion for that word "savagery"are the labels which we civilised folk apply respectively to two forms of human culture apparently so unlike that it is hard to conceive that they had a common origin--our own culture and that other, the most primitive form of human culture, from which, at some unknown and distant period, our own diverged. But, assuming one common origin for the whole human race, we anthropologists can but assume that at an early stage in the history of that race some new idea was implanted in a part of these folls, that is, in the ancestors of civilised folk, which caused these thenceforth to advance continuously, doubtless by many again subsequently diverging and often intercrossing roads, some doubtless more rapidly than others, but all mainly towards that which is called civilisation, while those others, those whom we call "savages," were left behind at that first parting of the ways, to stumble blindly, advancing indeed after a fashion of their own, but comparatively slowly and in a quite different direction.

It is easy enough for civilised folk, when after age-long separation they again come across the "savages," to discern the existence of wide differences between the two, in physical and mental characteristics, and in arts and crafts; it is not so easy, it may even be that it is impossible, to detect the exact nature of these differences, especially in the matter of mental characters.

As a rule the occupant of this presidential chair is one who, whether he has seen much of "savages" at close quarters or not, has had much ampler opportunity than has fallen to my lot of comparative study of that great mass of anthropological observations which, gathered from almost every part of the world, has now been recorded at headquarters. I, on the other hand, happen to have spent the better part of my active life in two different parts of the world, remote from books and men of science, but in both of which folk of civilised and of savage culture have been more or less intermixed, but as yet very imperfectly combined, and in both of which I have been brought into rather unusually close and sympathetic contact with folk who, whatever veneer of civilisation may have been put upon them, are in the thoughts which lie at the back of their minds and in character still almost as when their ancestors were at the stage of savage culture.

While trying to adjust the mutual relations of wild folk and of folk of civilised stock, I have seen from close at hand the clash which is inevitable when the two meet-a clash which is naturally all the greater when the meeting is sudden. Moreover, having started with a strong taste for natural history, and 